\title{
40th anniversary of the EAHP: the past and the future
}

\section{Roberto Frontini}

You might ask whether 40 years in existence means being a young or an old association. The European Association of Hospital Pharmacists (EAHP) is young and old. It is like in life: the passing time gives you experience but life means looking into the future. Keeping the curiosity of a child while being an old man with long experience is what we call wisdom.

Looking back to the first years of the EAHP, let us understand how difficult it was for the founders to create a European understanding. At that time even language was a burden, in a time where a global world was not a reality and the iron curtain was splitting Europe. Our colleagues had to learn to communicate. They had to focus on the organisation of the new association, which meant focusing on internal matters necessary to create what the EAHP is

Correspondence to Dr R Frontini, EAHP President, Universitätsklinikum Leipzig Liebigstrasse 20,

D-04103 Leipzig, Germany; president@eahp.eu today. The EAHP began growing, starting with the congress as an educational and scientific event, but still focusing on hospital pharmacy as a profession.

My predecessors were the heroes who created the strong association we are today. The EAHP is now a mature adult.

Since the very beginning, hospital pharmacists and the EAHP were engaged in helping patients but this was not well communicated. We must now rethink our profession from the perspective of the patient. What makes our profession an added value? What makes our profession unique for the best clinical outcome? Why do hospital pharmacists make a difference in medication use?

The change in the EAHP logo in 2010 was the start of this new understanding of hospital pharmacy as a profession dedicated to patients and this is symbolised by the cross

A strong tree has strong roots and the root of our profession is the production of the best medicines for patients. Being at the patient's bed as part of the healing team must be linked to the production of individualised medicines at the highest level in hospital pharmacy.

A society grows great when old men plant trees whose shade they know they shall never sit in, ancient Greek wisdom says. The founders of 1972 seeded the now 40-year-old tree of the EAHP but the oldest of them are no longer with us to see what they created. We are now the old people who have to plant the future trees which we will see only as a shoot.

We are the pharmacists who have to change our education and profession to be more and more patient oriented.

The understanding of history is the means for creating the future.

\section{Competing interests None.}

Provenance and peer review Not commissioned; not externally peer reviewed.

Accepted 24 January 2012

European Journal of Hospital Pharmacy 2012;19:4. doi:10.1136/ejhpharm-2012-000080 